\title{
Planetary Boundary Layer Height Estimation from Doppler Wind Lidar Measurements, Radiosonde and Hysplit Model Comparison
}

\section{Estimación de la Altura de la Capa Límite Planetaria con Medidas de Lidar Doppler de Viento, y Comparación con Radiosonda y Modelo Hysplit}

\author{
G. de A. Moreira ${ }^{1}$, M. T. A. Marques ${ }^{1}$, W. Nakaema ${ }^{1}$, A. C. de C. A. Moreira ${ }^{2}$, E. Landulfo ${ }^{1}$ \\ 1. CLA, IPEN/CNEN, Center for Lasers and Applications, Av. Prof. Lineu Prestes, 2242, Cidade Universitária, \\ São Paulo - SP - Brazil, 05508-915 \\ 2. PETROBRAS - Petróleo Brasileiro S. A. Research Center - CENPES, Av. Horácio Macedo, 950, Rio de Janeiro \\ - RJ - Brazil, 21941-915 \\ ${ }^{*}$ E-mail: gregori.moreira@usp.br
}

Received / Recibido: 15/05/2015 Accepted / Aceptado: 26/08/2015

DOI: $10.7149 /$ OPA.48.3.179

\begin{abstract}
:
This work aims to estimate the planetary boundary layer height from data of a wind Doppler lidar in the south of Brazil, and compare its results to radiosonde and Hysplit model data. By means of this comparison is expected to acquire a better comprehension about wind Doppler lidar skills and limitations applied in environmental science.
\end{abstract}

Key words: Wind Doppler Lidar, PBL Height, Radiosonde, Hysplit

\section{REFERENCES AND LINKS / REFERENCIAS Y ENLACES}

[1] V. A. Kovalev, W. E. Eichinger, Elastic lidar: Theory, practice and analysis methods. New Jersey: John Wiley \& Sons (2004). http://dx.doi.org/10.1002/0471643173

[2] W. P. Hooper, E. W. Floranta, "Lidar measurements of wind in the planetary boundary layer: The method, accuracy and results from joint measurements with radiosonde and kytoon," J Appl Meteor Climatol 25, 990-1001 (1985). http://dx.doi.org/10.1175/1520-0450\%281986\%29025<0990\%3ALMOWIT>2.0.C0\%3B2

[3] T. E. VanZandt, J. L. Green, K. S. Gage, W. L. Clark, "Vertical profiles of refractivity turbulence structure constant: Comparison of observations by sunset radar with a new theoretical-model," Radio Science 13, 819-829 (1978). http://dx.doi.org/10.1029/RS013i005p00819

[4] NOAA National Weather Service, "Radiosonde Observations," http://www.ua.nws.noaa.gov/factsheet.htm

[5] W. M. Angevine, A. B. White, S. K. Avery, "Boundary-layer depth and entrainment zone characterization with a boundary-layer profiler," Boundary-Layer Meteorology 68, 375-385 (1994). http://dx.doi.org/10.1007/BF00706797

[6] J. C. Wyngaard, M. A. Lemone, "Behavior of the refractive-index structure parameter in the entraining convective boundary-layer," J Atmos Sci 37, 1573-1585 (1980). http://dx.doi.org/10.1175/1520-0469(1980)037<1573:BOTRIS>2.0.CO;2

[7] J. M. Wallace, M. A. Hobbs, Atmospheric sciences: An introductory survey. California: Elsevier (2006). 


\section{Introduction}

Remote sensing devices has been largely utilized in environmental applications [1]. They have been appointed by many authors [1,2] as one of the best tools to obtain information of atmosphere, because they provide good description and characterization of the troposphere, mainly because they have a good spatial and temporal resolutions.

When it comes to wind, wind Doppler lidar deserves to be highlighted, because it enables different types of studies, which vary from observations of vertical wind profile until the detection of turbulent phenomena [1,3], so that, this device has been largely used in academic studies and in commercial applications.

\section{Methodology}

The measurement campaign was held in Ressacada's Farm $\left(27^{\circ} 40^{\prime} \mathrm{S}, 43^{\circ} 30^{\prime}\right)$ Santa Catarina State - South of Brazil, during December 2014.

\section{2.a. Instruments}

A pulsed lidar model WLS70 from Leosphere, was used to measure meteorological quantities from 100 to $1000 \mathrm{~m}$, with spatial (vertical) resolution of $20 \mathrm{~m}$, being that all heights in this range were used in this paper. It performs a velocity azimuth display (VAD) technique with $14.93^{\circ}$ conical angle. The data are averaged in 10-min intervals and as an indicator of the measurement quality were used the following parameters: Data Availability [\%] (the ratio of measurement points accepted by built-in data filters over the complete set of measurement) and Carrier to Noise Ratio (CNR), which is equivalent to the Signal to Noise Ratio (SNR). The CRN threshold is set up as $-29 \mathrm{~dB}$.

For this study was used radiosonde data measured in the international airport of Florianópolis (SBFL), 1.6 $\mathrm{km}$ northwest from the lidar site. The radiosonde site is operated by the meteorological network of the aerospace command (REDEMET) and the radiosondes are launched twice a day at 00 and 12 UTC. The spatial and temporal resolution of the radiosonde depends on the balloon trajectory, wind and stability conditions. The balloon rises around $300 \mathrm{~m} / \mathrm{min}$, can ascend to over $35 \mathrm{~km}$, drift more than $300 \mathrm{~km}$ from the release point and can last 2 hours [4].

We also used the Hybrid Single-Particle Lagrangian Integrated Trajectory model (Hysplit) to simulate the radiosonde observations. This model offers a temporal resolution of 3 hours and variable spatial resolution as well as the radiosonde.

\section{2.b. Planetary Boundary Layer (PBL) height}

The signal received by lidar is coming from inhomogeneities in atmosphere, which are characterized by the refractive index structure parameter $\left(C_{n}{ }^{2}\right)$ [5]. Wyngaard [6] showed that it is possible to use $C_{n}{ }^{2}$ value to find the PBL height in convective situations, because it has a peak in top of this layer. Van Zandt [3] evinced the proportionality between $C_{n}{ }^{2}$ and SNR range-corrected values, so it is possible to conclude that we can use SNR values to detect PBL height [5], being that the top of PBL is equivalent at maximum value of SNR profile.

\section{2.c. Bulk Richardson Number (BRN)}

The BRN (eq. 1) is a relation between potential and kinetic energy [7], where $\mathrm{g}\left[\mathrm{m} / \mathrm{s}^{2}\right]$ is the gravity acceleration, $\theta_{v}[K]$ is the potential temperature, $\mathrm{u}[\mathrm{m} / \mathrm{s}]$ and $\mathrm{v}[\mathrm{m} / \mathrm{s}]$ are the horizontal wind components and $b u_{*}^{2}\left[\mathrm{~m}^{2} / \mathrm{s}^{2}\right]$ is a constant related to surface friction effects; the suffix $s$ and $z$ refer to surface and height respectively.

$$
B R N=\frac{\frac{g}{\theta_{v s}}\left(\theta_{v z}-\theta_{v s}\right)\left(z-z_{s}\right)}{\left(u_{z}-u_{s}\right)^{2}+\left(v_{z}-v_{s}\right)^{2}+\left(b u_{*}^{2}\right)},
$$

This number enables to detect different turbulent regimes in atmosphere. PBL has turbulent activities more intense than free atmosphere, so that, BRN has different values in these layers. Therefore, if the standard value of critical BRN $\left(C_{B R N}\right)$, in transition of these layers, is known, it is possible to estimate the PBL height. Although there are some divergences about more precise value, often the range is about 0.25 to 0.30 [7]. In this paper the value adopted is 0.25 . 
The information used to obtain BRN come from radiosonde data (12 UTC) and Hysplit model (a point every 3 hour), which provide radiosonde emulated data each 3 hours, as mentioned above.

\section{Results}

The lidar and the radiosondes observations represent different measurements of the wind field, the lidar winds are averaged in time and space according to the VAD technique, in contrast, the radiosonde averages the wind along the balloon trajectory. This effect, coupled with atmospheric variability induces differences in the wind observations not caused by instrumental errors. [2] The Fig. 01 shows the wind profile observed by the lidar, radiosonde and Hysplit, the different mechanisms used to calculate the PBL height.
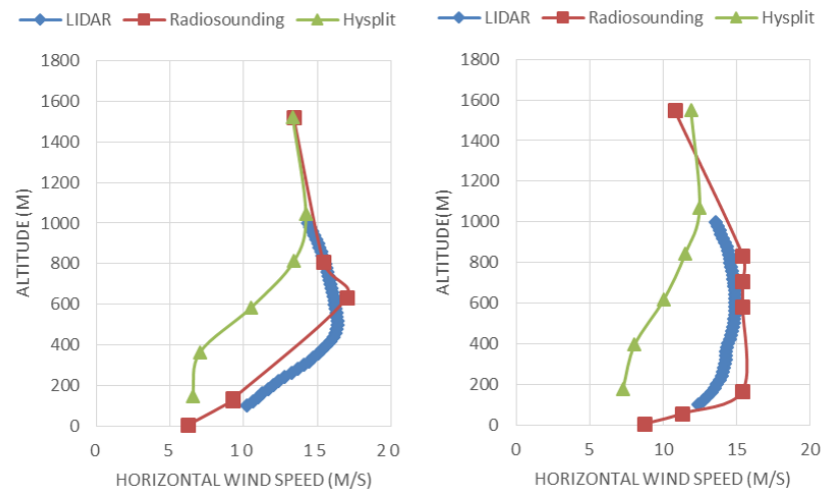

Fig. 1. Horizontal wind profile - Ressacada's Farm - Brazil - 23/12/2014 00 UTC (left) 12 UTC (right).

The Fig. 2 shows a comparison between the three mechanisms used to obtain PBL height: BRN (Hysplit and radiosonde) and CNR. In background of this graphic, it was inserted a parameter named Data Availability.

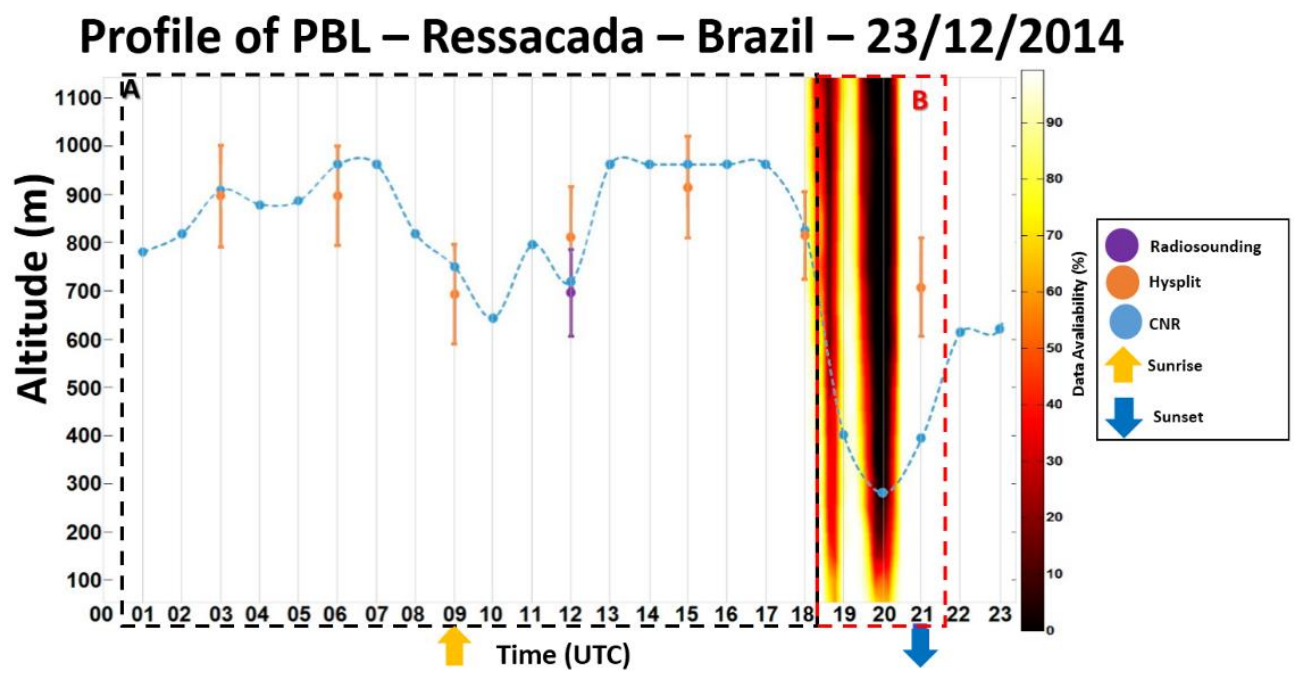

Fig. 2. Profile of the PBL - Ressacada's Farm - Brazil - 23/12/2014.

The case A comprehends from 01 until 18 UTC. Along this period, the data availability keeps high values and there is high proximity among values obtained from lidar data and BRN from radiosonde and Hysplit. The Fig. 3 shows a comparison among these three mechanisms at 12 UTC. 

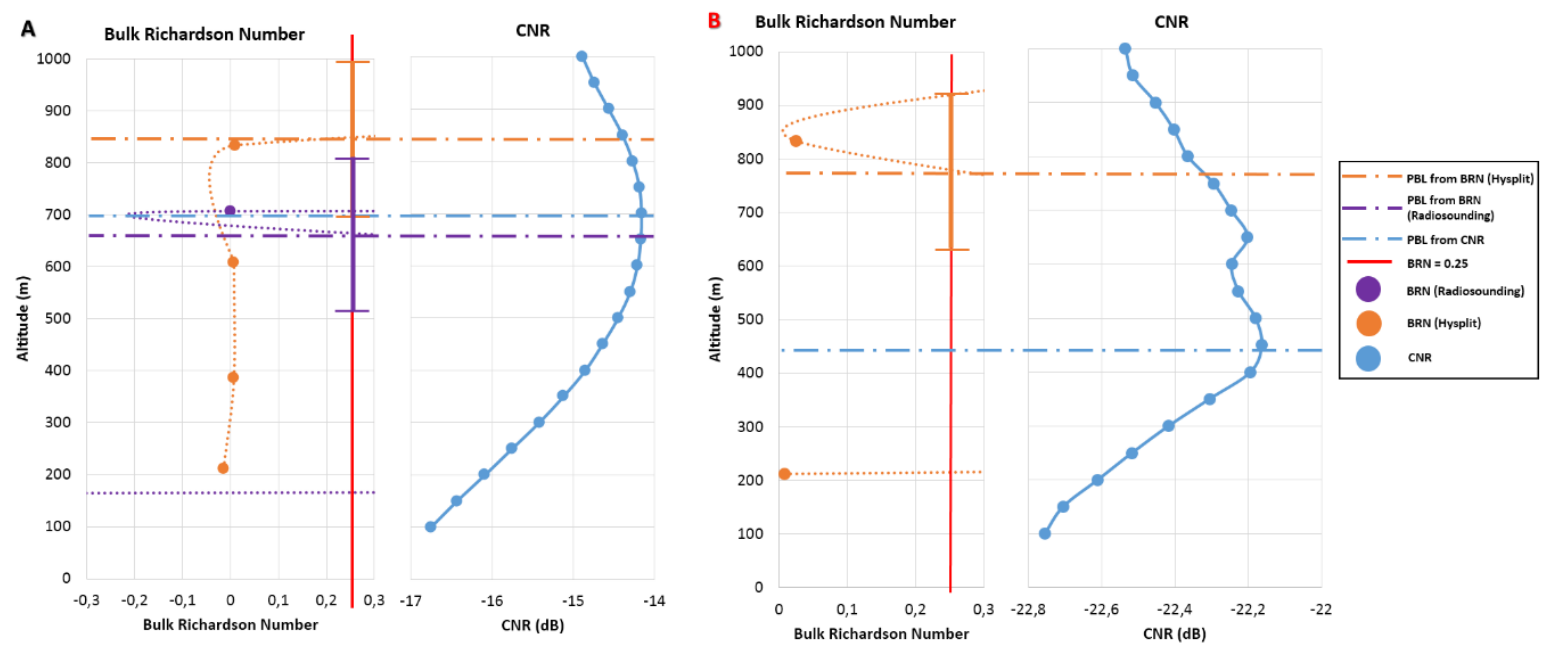

Fig. 3. Comparison among lidar, radiosonde and Hysplit. Case A (Left) - Case B (Right).

Due to small quantity of points in radiosonde data and low spatial resolution, sometimes the comparison between Hysplit and radiosonde is not so near. Because this uncertainty, it was inserted error bars created according to average of two heights near point selected.

BRN points calculated by Hysplit and radiosonde have similar profiles and they are spaced from each other thereabout $126 \mathrm{~m}$. These two points are near height obtained from CNR method, but radiosonde data has higher proximity $(26 \mathrm{~m})$ than Hysplit $(100 \mathrm{~m})$. Along all period, the PBL heights obtained from CNR method are inner range of each point generated by Hysplit data.

The case B covers some minutes after 18 until 21:30 UTC. During this period the data availability has small values, so that, the correlation between Hysplit and CNR Method is small, the difference between them is $345 \mathrm{~m}$.

Although the low values of data availability are not exactly under the Hysplit and CNR point in graph, these values have interference, because they are used to calculate the average hourly in CNR method.

From these two situations, it was possible to observe the high skill of lidar data to provide PBL height, the majority of points are situated inner the range of BRN data, with the exception of point situated in case B, as discussed. The Fig. 04 shows the difference between BRN from Hysplit and CRN. In case A the mean difference between them is $52.10 \mathrm{~m}$, being that at 18 UTC this difference is around $10 \mathrm{~m}$. Whereas in case $B$ the difference is $345 \mathrm{~m}$.
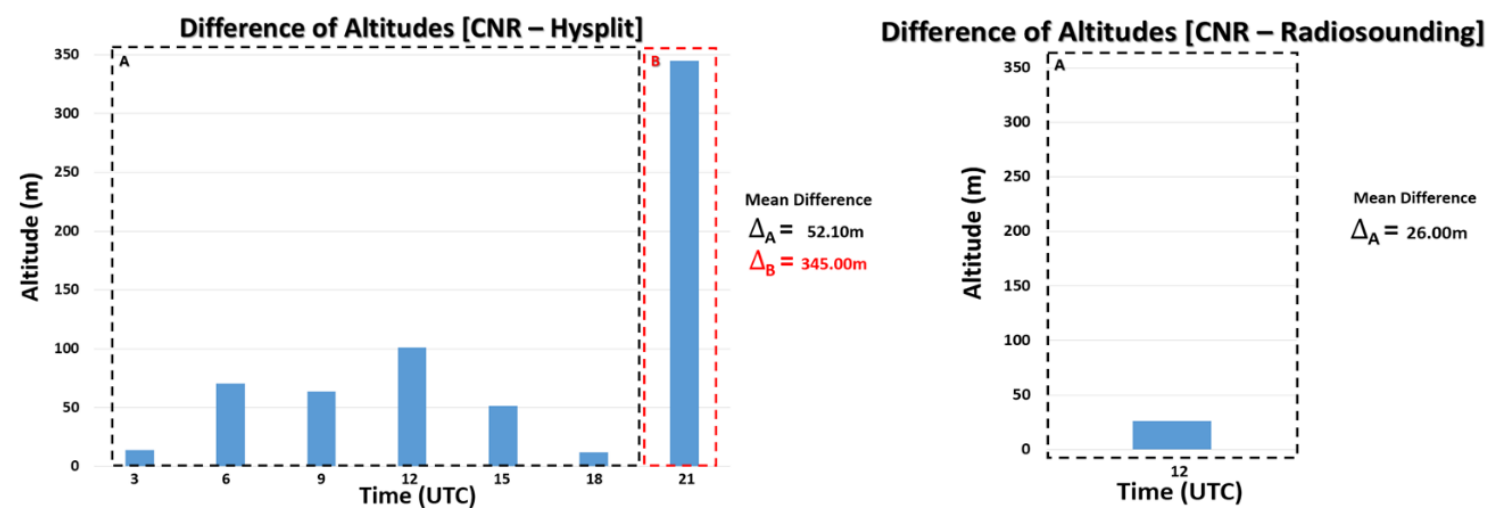

Fig. 4. Difference between PBL height from lidar and Hysplit (right) and from lidar and radiosonde (left).

\section{Conclusions}

The value of PBL height obtained by the wind Doppler lidar has a significant proximity to the value obtained for the radiosonde that we use here as a reference. In the same time, the Hysplit model gives values with reasonably proximity as obtained from CNR method, considering the errors bars. In accordance to this, as we can see in Fig. 01 through the horizontal wind speed vertical profile, there is a 
better correspondence between the lidar and the radiosonde, despite its technical limitations, than the lidar and the Hysplit model.

However, for most of the moments, the Hysplit model is the only method we can compare with lidar results and it shows an acceptable proximity except in the case where the data availability is low.

In order to have better and accurate results we see the necessity to extend the period of comparison and at the same time improve the temporal resolution of the radiosonde, but, as a limitation out of the boundaries of this study, an option is to improve the modeling results to the comparison.

\section{Acknowledgements}

This work is supported by the funding agency CAPES. The authors gratefully acknowledge the work team from Ressacada's Farm (UFSC) for valuable assistance and routine maintenance of the lidar, in special Yoshiaki Sakagami and Pedro A. A. Santos and the companies Leosphere and Campbell Scientific Brazil. 